\title{
Extração Ácida da Pectina da Casca de Maracujá
}

\section{e-Xacta}

ISSN: 1984-3151

\section{ASSISTIDA POR ULTRASSOM}

\author{
Acid Extraction of the Pectin from Passion Fruit Peel \\ ASSISTED BY ULTRASOUND
}

\section{Giovana de Menezes Rodrigues ${ }^{1}$; Camila da Silva²}

1 Graduada em Engenharia de Alimentos. Universidade Estadual de Maringá, 2016. Umuarama, PR. giovanademr@gmail,com.

2 Doutora em Engenharia Química. Universidade Estadual de Maringá, 2009. Professora do Departamento de Tecnologia. Universidade Estadual de Maringá, Umuarama, PR. camiladasilva.eq@gmail.com.

Recebido em: 14/02/2017 - Aprovado em: 05/05/2017 - Disponibilizado em: 31/05/2017

RESUMO: A pectina é um polissacarídeo complexo, que atua como agente geleificante, espessante e estabilizante na composição de diversos produtos. A casca do maracujá possui elevado nível de pectina, cujo método convencional de extração é a ebulição utilizando ácidos fortes. O presente estudo objetivou explorar um novo método de extração utilizando ácidos fracos. Buscando esse propósito, a pectina da casca de maracujá foi obtida por meio de extração assistida por ultrassom, utilizando solução de ácido cítrico. Os experimentos foram conduzidos visando avaliar o efeito das variáveis experimentais (razão amostra:solvente, temperatura e tempo) no rendimento de pectina. Os resultados demonstraram que a extração conduzida com razão amostra:solvente de 1:50 (m/ v), temperatura de $50{ }^{\circ} \mathrm{C}$ e tempo de 90 min proporcionou a obtenção de $26,45 \%$ de pectina. Nessas mesmas condições experimentais a pectina foi extraída por método convencional para efeito comparativo, o qual permitiu a obtenção de $21,06 \%$ de pectina. Portanto, o uso do ultrassom promoveu a obtenção de melhores resultados, visto que proporcionou o aumento de $25 \%$ no rendimento. O grau de esterificação foi determinado apenas para amostras obtidas por ultrassom, as quais foram classificadas com alto grau de metoxilação $(81,93 \%)$. PALAVRAS-CHAVE: Ultrassom. Ácido cítrico. Pectina.

ABSTRACT: Pectin is a complex polysaccharide, which acts as a gelling agent, thick and stabilizing in the composition of various products. The passion fruit peel has a high level of pectin, whose conventional method of extraction is boiling using strong acids. The present study aimed to explore a new extraction method with the weak acids. For this purpose, a pectin from the passion fruit peel was obtained by ultrasound-assisted extraction, using citric acid solution. The experiments were conducted with the objective of evaluating the effect of experimental variables (analysis procedure: solvent, temperature and time) on pectin yield. The results demonstrated that the extraction was carried out on the basis of a solvent criterion of $1: 50(\mathrm{~m} / \mathrm{v})$ at a temperature of $50{ }^{\circ} \mathrm{C}$ and the time of 90 minutes provided a yield of $26.45 \%$ pectin. In these same experimental conditions the pectin was extracted by conventional method for comparative effect, which allowed a obtainment of $21.06 \%$ pectin. Consequently, the use of the product was promoted to obtain better results, which gave rise to a $25 \%$ of increase in yield. The degree of esterification was determined only for samples obtained by ultrasound, which were classified with high degree of methoxylation (81.93\%).

KEYWORDS: Ultrasound. Citric acid. Pectin. 


\section{INTRODUÇÃO}

O gênero Passiflora possui mais de 520 espécies, sendo 150 nativas do Brasil (BERNACCl et al., 2008). A importância do maracujazeiro no país é vista pelo volume produzido da fruta. O maracujá amarelo (Passiflora edulis flavicarpa) é o mais cultivado e consumido no país, representando $95 \%$ dos pomares, devido à qualidade dos seus frutos, produtividade $\mathrm{e}$ rendimento em suco da polpa (MELETTI, 2011).

O maracujá é composto por $53 \%$ de casca (albedo e flavedo), $20,90 \%$ de semente e $26,10 \%$ de polpa (OLIVEIRA et al., 2002). A maior importância econômica do fruto está no produto industrializado, principalmente na extração da polpa para produção de suco (SANTOS et al., 2017).

De acordo com Oliveira et al. (2002) os subprodutos obtidos a partir do processamento do maracujá correspondem de 60 a $70 \%$ do peso do fruto. Desses subprodutos gerados podem ser produzidos farinhas da casca tratadas, massa base espessante (rica em fibras), pectina, aromas e óleos (COSTA, 2013). A casca do maracujá é rica em fibras solúveis, como a pectina, importante no controle dos níveis sanguíneos de glicídios e lipídios (BONFIETTI, 2017). Podendo auxiliar na prevenção de doenças gastrointestinais, diabetes e obesidade (COQUEIRO; PEREIRA; GALANTE, 2016).

A pectina é um polissacarídeo complexo conhecido por suas inúmeras propriedades, que permitem seu uso como agente geleificante, espessante e estabilizante, sendo de grande importância nas áreas da ciência de alimentos e bebidas, nutrição, cosmética e farmacêutica (LIEW; CHIN; YUSOF, 2014).

O processo de extração é fundamental para a produção da pectina cítrica e o método mais comum de extração emprega solução de ácido mineral forte diluído quente (VRIESMANN; TEÓFILO; PETKOWICZA, 2012). Porém ácidos fortes são corrosivos e causam efeitos adversos à saúde. Além disso, os efluentes corrosivos gerados pelos ácidos convencionais causam impactos ambientais. Visando o interesse da indústria na produção de pectina, tornase necessário o estudo de uma metodologia de extração que minimize os danos provocados ao ambiente (MINJARES-FUENTES et al., 2014; PINHEIRO et al., 2008). A substituição dos ácidos fortes (ácidos clorídrico, nítrico, tartárico, sulfúrico), por ácidos orgânicos fracos como ácido cítrico pode contribuir para esse fim (YAPO, 2009). O ácido cítrico tem se mostrado eficaz na extração de pectina garantindo bom rendimento e evitando a degradação da molécula péctica. $O$ ácido cítrico é vantajoso do ponto de vista econômico e atua como um aditivo alimentar natural (CANTERI-SCHEMIN et al., 2005; PINHEIRO et al., 2008).

A extração assistida por ultrassom tem se destacado como uma técnica inovadora aplicável a diversas matrizes vegetais (MINJARES-FUENTES et al., 2014; CHEN; FU; LUO, 2015). Essa técnica tem permitido aumentar a eficiência da extração, consumindo menor energia e solvente e, assim, tem sido amplamente utilizado para obtenção de pectina (MARAN; PRIYA, 2015). O mecanismo da extração assistida por ultrassom é atribuído à força mecânica e à cavitação, que em conjunto com aquecimento do sistema, resultam no rompimento das paredes celulares do material vegetal e redução do tamanho das partículas, promovendo o aumento a transferência de massa (VILKHU et al., 2008).

Com base no contexto descrito, o objetivo do presente estudo foi a obtenção de pectina da casca de maracujá, utilizando ácido cítrico como agente extrator em banho ultrassônico. Buscando esse propósito, foi avaliado o efeito das variáveis experimentais (razão amostra:solvente, temperatura e tempo) no rendimento em pectina, bem como a determinação do grau de esterificação da amostra obtida por ultrassom nas melhores condições experimentais. A extração 
pelo método convencional foi realizada para efeito comparativo.

\section{MATERIAIS e MÉtodos}

\subsection{ESPECIFICAÇÃo dOS MATERIAIS}

Foram utilizados frutos de maracujá amarelo (Passiflora edulis flavicarpa), sem cortes exteriores visíveis ou deterioração, coletados no mercado local de Umuarama no estado do Paraná, Brasil. Para a extração e isolamento da pectina foram utilizados ácido cítrico (Anidrol, 99,5\%) e álcool etílico (Anidrol, 95\%). Para determinação do grau de esterificação utilizaram-se hidróxido de sódio (Anidrol, 97\%), ácido clorídrico (Dinâmica, 37,25\%) e fenolftaleína P.A.

\subsection{Preparo e Caracterização da Matéria- Prima}

Os frutos foram lavados, higienizados e cortados na horizontal, sendo as sementes e as polpas removidas. As cascas (composta de albedo e flavedo) passaram por processo de branqueamento conforme descrito por Oliveira et al. (2015), sendo imersas em água a temperatura de $100{ }^{\circ} \mathrm{C}$ durante $3 \mathrm{~min}$, seguido por resfriamento em banho de gelo. Após o branqueamento as cascas foram cortadas em pequenos pedaços e submetidas a secagem em estufa com circulação de ar (Marconi, MA 035), por $48 \mathrm{~h}$ a $60^{\circ} \mathrm{C}$. O material foi triturado em moinho de facas (Willy, MSSL-031) para obtenção de farinha fina e esta foi acondicionada em saco de polietileno à temperatura ambiente.

As análises de composição centesimal foram realizadas conforme indicado pelo Instituto Adolfo Lutz (2008).

\subsection{EXTRAÇÃo AsSistida POR ULTRASSOM}

A pectina foi extraída utilizando potência ultrassônica constante em banho de ultrassom com dimensões internas de $30 \mathrm{~cm} \times 15 \mathrm{~cm} \times 15 \mathrm{~cm}$, com capacidade de $5,9 \mathrm{~L}$, potência de $165 \mathrm{~W}$ e frequência de $25 \mathrm{kHz}$ (Ultronique, Q 5.9/40A). As condições variáveis foram razão amostra:solvente (01:15, 01:25, 01:35 e 01:50 g $\left.\mathrm{mL}^{-1}\right)$, temperatura $\left(40,50\right.$ e $\left.60^{\circ} \mathrm{C}\right)$ e tempo $(15,30$, 60,90 e $120 \mathrm{~min}$ ). A farinha da casca de maracujá $(3 \mathrm{~g})$ foi pesada em Erlenmeyer $(250 \mathrm{~mL})$ utilizando balança semi-analítica (Shimadzu, UX420H) e posteriormente foi adicionada água acidificada com ácido cítrico, com concentração corrigida em pH 2,00 (OLIVEIRA et al., 2015). Esse foi conectado ao condensador acoplado a banho refrigerado (Marconi, MA 184). Após o período de extração, a amostra foi filtrada em papel qualitativo, com diâmetro de $15 \mathrm{~cm}$ e gramatura de 80 g.m $\mathrm{m}^{-1}$ e obteve-se o filtrado contendo a pectina. Os experimentos foram realizados em duplicada para cada condição experimental avaliada.

\subsection{Extração Convencional}

A extração convencional foi conduzida sob as melhores condições designadas por ultrassom (temperatura de $50{ }^{\circ} \mathrm{C}$, tempo de 90 min e razão amostra:solvente de 1:50 g.mL $\mathrm{mL}^{-1}$ ), sendo os experimentos realizados em duplicata. A extração foi realizada conforme metodologia de Canteri-Schemin et al. (2005), com ligeiras modificações. O procedimento foi conduzido em balão de três bocas, submerso em água aquecida por chapa de aquecimento e agitação magnética de $400 \mathrm{rpm}$ (IKA, RCT). No balão foi adicionada a solução acidificada $\mathrm{pH}$ 2,00 e este foi conectado ao condensador acoplado a banho refrigerado (Marconi, MA 184). Ao atingir a temperatura de interesse $\left(50{ }^{\circ} \mathrm{C}\right)$, foi adicionada a farinha da casca de maracujá (3 g). Após o período de extração, a amostra foi filtrada em filtro de papel e obteve-se o filtrado contendo a pectina. 


\subsection{Isolamento da Pectina}

Realizado para ambos os métodos de extração conforme metodologia de Moorthy et al. (2015). O isolamento da pectina consistiu em adicionar ao filtrado etanol 95\% (1:2 v/v), em seguida, a mistura foi brevemente agitada ( 1 $\mathrm{min}$ ) e deixada em repouso à temperatura ambiente por $1 \mathrm{~h}$ para permitir a precipitação completa da pectina. A pectina precipitada foi filtrada, acondicionada em placa petri, e secada em estufa com circulação de ar (Marconi, MA 035) a $60{ }^{\circ} \mathrm{C}$ até peso constante. $\mathrm{O}$ rendimento foi calculado a partir da Equação 1.

$$
\text { Rendimento(\%) }=\left(\frac{m_{0}}{m}\right) \times 100 \%
$$

na qual: $m_{0}=$ peso de pectina seca $[\mathrm{g}], m=$ peso da farinha da casca de maracujá [g].

A análise estatística dos resultados foi realizada utilizando o software Microsoft ${ }^{\circledR}$ Excel 2010 para avaliar a análise de variância (ANOVA) e aplicar o teste de Tukey, a fim de verificar o efeito das variáveis estudadas e diferenças significativas em um intervalo de confiança de $95 \%(p<0,05)$.

\subsection{GRAU DE EsterificAÇÃo (GE)}

A pectina seca foi triturada em moinho (Cadence, BLD 300) para obtenção de um pó fino, para realização do grau de esterificação, o qual foi determinado pelo método de titulação reportado Liew, Chin e Yusof (2014). A metodologia consistiu em umedecer com etanol $(5 \mathrm{~mL})$ a pectina triturada $(0,2 \mathrm{~g})$, adicionar 20 $\mathrm{mL}$ de água destilada e aquecer a mistura a $45^{\circ} \mathrm{C}$ por $40 \mathrm{~min}$ em incubadora refrigerada (Marconi, MA 839/A) com agitação de $40 \mathrm{rpm}$. Posteriormente, três gotas de fenolftaleína foram adicionadas à amostra e esta foi titulada com solução de $\mathrm{NaOH} 0,1 \mathrm{~mol}^{-\mathrm{L}^{-1}}$. Anotou-se o volume inicial gasto na titulação como $v_{i}$. Em seguida, $10 \mathrm{~mL}$ de solução de $\mathrm{NaOH} 0,1 \mathrm{~mol} \mathrm{~L}^{-1}$ foram adicionados à amostra já titulada e agitou-se. A mistura foi deixada repousar a temperatura ambiente durante $2 \mathrm{~h}$ para a desterificação da pectina. Adicionou-se $10 \mathrm{~mL}$ de solução de $\mathrm{HCl} 0,1 \mathrm{~mol}^{-1} \mathrm{e}^{-1} \mathrm{e}$ esta foi agitada até que a cor rosa desaparecesse. Três gotas de fenolftaleína foram adicionadas à amostra e esta foi titulada novamente com solução de $\mathrm{NaOH}$ 0,1 mol.L-1. Anotou-se o voume final gasto na titulação como $v_{\text {f. }}$ O GE foi calculado a partir da Equação 2.

$$
G E(\%)=\left(\frac{v_{f}}{v_{i}+v_{f}}\right) \times 100 \%
$$

em que: $v_{i}=$ volume inicial gasto $[\mathrm{mL}], v_{f}=$ volume final gasto $[\mathrm{mL}]$.

\section{Resultados e Discussão}

\subsection{Caracterização da Matéria-Prima}

Os resultados das análises de composição centesimal da casca de maracujá são apresentados na Tabela 1.

\section{Tabela 1}

Composição físico-química da casca de maracujá.

\begin{tabular}{c|c}
\hline Componente & $(\%)$ \\
\hline Umidade & $6,41 \pm 0,11$ \\
Cinzas & $5,85 \pm 0,14$ \\
Proteínas & $4,51 \pm 0,03$ \\
Lipídeos & 0,22 \\
Fibra Bruta & $25,96 \pm 0,15$ \\
Carboidratos & $56,98 \pm 0,02$ \\
\hline
\end{tabular}

O conteúdo de umidade, cinzas, proteínas, lipídios e fibra bruta foram semelhantes aos encontrados na literatura para a farinha da casa de maracujá (PINHEIRO et al., 2008; UCHOA et al., 2008; 
OLIVEIRA et al., 2015). A farinha da casca de maracujá apresentou umidade de $6,41 \pm 0,11 \%$, muito próxima à umidade obtida por Oliveira et al. (2015) de $6,61 \pm 0,36 \%$. O conteúdo de cinzas foi de $5,85 \pm$ $0,14 \%$, estando na média entre os resultados obtidos por Pinheiro et al. (2008) de 9,27 $\pm 0,05 \%$ e Uchoa et al. (2008) de 2,52 $\pm 1,16 \%$. O teor de lipídios foi de $0,22 \%$, estando acima do teor de lipídeos reportado por Pinheiro et al. (2008) menor que 0,10\%, e inferior ao reportado por Uchoa et al. (2008) de $0,75 \pm 0,13 \%$. O conteúdo de fibra bruto foi de 25,96 $\pm 0,15 \%$, estando próximo ao resultado reportado por Uchoa et

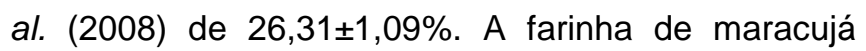
apresentou $56,98 \pm 0,02 \%$ de carboidratos, enquanto que Oliveira et al. (2002) obtiveram 53,82 $\pm 0,21 \%$.

De acordo com Oliveira et al. (2002), certas variações entre os conteúdos são aceitáveis, visto que depende do local de plantio, das condições genéticas da planta, do estágio de maturação do fruto, que leva a perda de umidade, e afeta a concentração dos demais constituintes. Além de outros fatores como os reagentes utilizados para realização das análises e metodologias empregadas.

\subsection{Extração da Pectina por Ultrassom}

\subsubsection{Efeito da RazÃo Amostra:Solvente}

A Figura 1 apresenta 0 efeito da razão amostra:solvente no rendimento de pectina obtido a $50{ }^{\circ} \mathrm{C}$ e tempo de $60 \mathrm{~min}$.

Pode-se verificar que a razão amostra:solvente influenciou $(p<0,05)$ na extração por ultrassom, visto que com o aumento de 1:15 para 1:50 (m/v), o rendimento de pectina variou de 13,21 para $21,62 \%$. Segundo Maran e Priya (2015) a maior razão amostra:solvente promove o aumento da superfície de contato entre a matriz vegetal e o solvente, o que favorece a transferência de massa.

Além disso, a extração assistida por ultrassom melhora a hidratação do material, elevando o rendimento do processo (TOMA et al., 2001). Quando o meio é concentrado e viscoso, a cavitação é reduzida, pois é necessário que a rarefação das ondas emitidas supere as forças de coesão naturais do líquido. Assim, quando o meio é menos concentrado a transmissão das ondas emitidas ocorre mais facilmente (GOGATE; PANDIT, 2004).

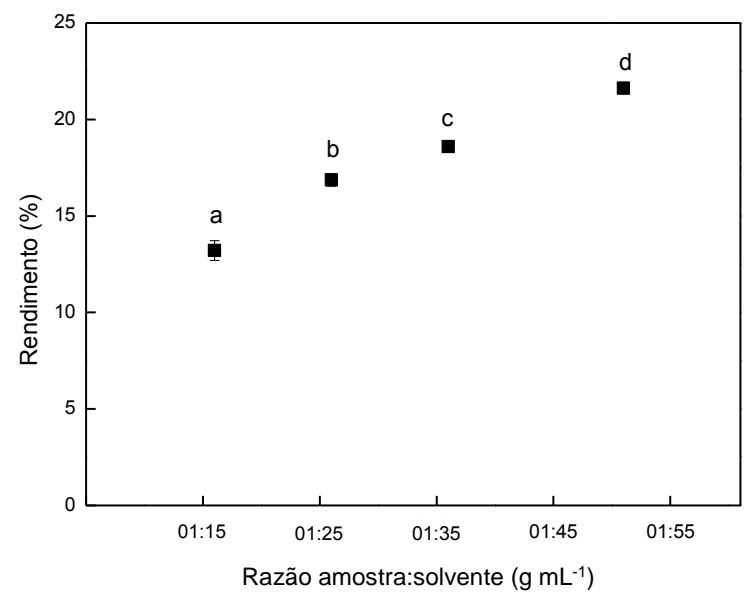

Figura 1 - Efeito da razão amostra:solvente no rendimento de pectina obtido a $50^{\circ} \mathrm{C}$ e $60 \mathrm{~min}$ Médias seguidas por letras diferentes indicam diferença significativa $(p<0,05)$ Fonte - Próprio autor.

\subsubsection{EfEITO dA TEMPERATURA}

A Figura 2 apresenta 0 efeito da temperatura no rendimento em pectina utilizando razão amostra:solvente de 1:50 (m/v) e 60 min de extração.

O rendimento de pectina aumentou de 18,39 para $21,62 \%$ quando a temperatura variou de 40 para 50 ${ }^{\circ} \mathrm{C}$. Esse fato pode ser explicado devido à maior solubilidade da pectina com o aumento da temperatura. No entanto, não houve diferença significativa $(p>0,05)$ no rendimento quando a extração foi conduzida a $60{ }^{\circ} \mathrm{C}$, o que pode ser parcialmente resultante da diminuição da potência de saída, uma vez que a temperatura afeta significativamente a potência de saída do ultrassom (XU et al., 2014). 


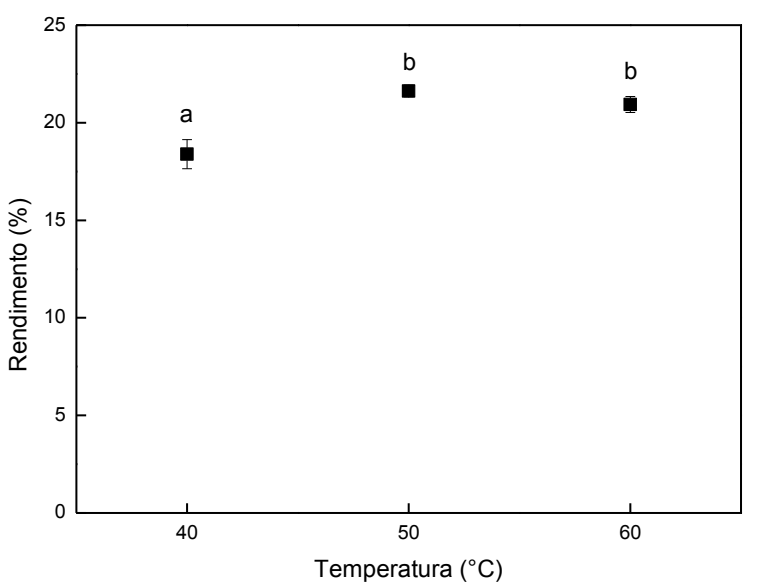

Figura 2 - Efeito da temperatura no rendimento de pectina utilizando razão amostra:solvente 01:50 (m/v) durante $60 \mathrm{~min}$

Médias seguidas por letras diferentes indicam diferença significativa $(p<0,05)$

Fonte - Próprio autor.

Chen, Fu e Luo (2015) reportaram melhor rendimento de pectina da polpa de beterraba quando a temperatura de extração variou de 80 para $120^{\circ} \mathrm{C}$. Porém houve decréscimo no rendimento quando a temperatura teste foi superior a $120^{\circ} \mathrm{C}$.

\subsubsection{EFEITO dO TEMPO}

Com o intuito de avaliar o efeito do tempo, a razão amostra:solvente e a temperatura foram mantidas fixas em 1:50 (m/v) e $50^{\circ} \mathrm{C}$, respectivamente.

A partir da Figura 3 verifica-se que o rendimento de pectina não foi influenciado pelo tempo até $60 \mathrm{~min}$, mas houve diferença significativa $(p<0,05)$ aos $90 \mathrm{~min}$ de extração.

Oliveira et al. (2016) estudaram o efeito do ultrassom na extração da pectina da casca de maracujá, sendo os experimentos realizados no intervalo 3 a 20 min e obtiveram maior rendimento (8,5\%) em $10 \mathrm{~min}$ de extração. Minjares-Fuentes et al. (2014) reportaram a extração por ultrassom da pectina do bagaço de uva utilizando ácido cítrico $\mathrm{pH} 2,00$, em que obtiveram rendimento máximo de $20 \%$ de pectina a $75{ }^{\circ} \mathrm{C}$ e 60 min de extração.

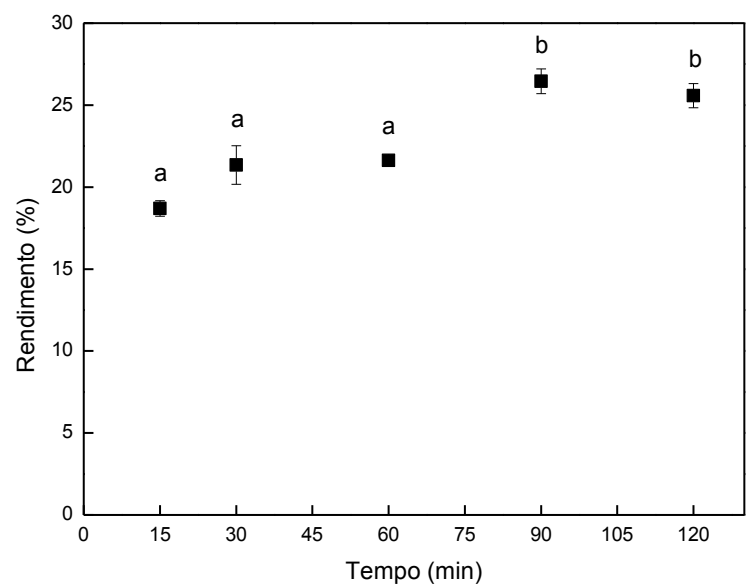

Figura 3 - Efeito do tempo no rendimento de pectina utilizando razão amostra:solvente $1: 50(\mathrm{~m} / \mathrm{v})$ e $50^{\circ} \mathrm{C}$ Médias seguidas por letras diferentes indicam diferença significativa $(p<0,05)$

Fonte - Próprio autor.

Xu et al. (2014) reportam que ocorre degradação da pectina quando exposta a temperaturas muito elevadas e ondas ultrassônicas durante um longo período de tempo.

\subsection{EFEITO dO ULTRASSOM NO PROCESSO}

A extração convencional foi realizada nas condições de maior rendimento obtidas no processo assistido por ultrassom (razão amostra:solvente 1:50 (m/v), tempo de $90 \mathrm{~min}$ e temperatura de $50 \stackrel{\circ}{\circ}$ ). Os resultados apresentados na Tabela 2 permitem verificar que o rendimento de pectina foi maior para a extração assistida por ultrassom $(p<0,05)$, com aumento de $25 \%$ no rendimento quando comparado ao método convencional.

Wang et al. (2015) estudaram a obtenção de pectina de toranja obtida a partir da extração assistida por ultrassom e por método convencional e concluíram que a extração por ultrassom proporcionou maior rendimento de pectina com temperatura mais baixa e menor tempo de extração. O efeito do ultrassom foi comparado com o método convencional na extração de pectina da casca de maracujá, realizada por Oliveira et al. (2016) e obtiveram rendimentos de 
12,76\% para extração por ultrassom e 7,95\% para extração por método convencional, utilizando para ambos temperatura de $85^{\circ} \mathrm{C}$, razão $1: 30(\mathrm{~m} / \mathrm{v})$, tempo de 10 min e solução de ácido nítrico pH 2,00.

Tabela 2

Rendimento de pectina da farinha da casca de maracujá obtido a partir da extração assistida por ultrassom e convencional.

\begin{tabular}{c|c}
\hline Método & Rendimento (\%) \\
\hline Ultrassom & $26,45 \pm 0,75^{\underline{a}}$ \\
Convencional & $21,06 \pm 0,19^{\mathrm{b}}$ \\
\hline
\end{tabular}

Médias seguidas por letras diferentes indicam diferença significativa $(p<0,05)$.

Fonte - Próprio autor.

\subsection{GRAU DE ESTERIFICAÇÃO}

O grau de esterificação foi determinado para apenas para amostras obtidas por ultrassom nas condições que proporcionaram maior rendimento de pectina e obteve-se $81,93 \%$ de grau de esterificação. De acordo com a literatura, a pectina acima de $50 \%$ de GE é vantajosa para fabricação de produtos com elevado teor de açúcar (CANTERI-SCHEMIN et al., 2005). Oliveira et al. (2016) estudaram a extração por ultrassom da pectina da casca de maracujá, utilizando solução de ácido nítrico pH 2,00 e obtiveram amostra com $60,36 \%$ de GE. Minjares-Fuentes et al. (2104) utilizaram a extração assistida por ultrassom na obtenção de pectina do bagaço de uva e reportam GE de 55,2\%. Liew, Chin e Yusof (2014) realizaram a otimização do processo de extração de pectina da casca de maracujá e relatam que o GE diminui com o tempo de extração, e dessa forma, obtiveram GE máximo de $58,92 \%$ em 30 minutos de extração. Os autores Kulkami e Vijayanand (2010) obtiveram GE de 88,2\% utilizando ácido clorídrico. Canteri-Schemin et al. (2010) e Pinheiro et al. (2008) obtiveram pectinas com grau de esterificação $68,84 \%$ e $78,59 \%$ utilizando ácido cítrico como agente extrator.

\section{Conclusão}

O aumento da razão amostra:solvente exerceu influência significativa $(p<0,05)$ no rendimento de pectina. Em relação ao tempo, períodos menores que 90 min apresentaram menor rendimento de extração e maiores, entre os testados, apresentaram rendimentos próximos, com $95 \%$ de confiança. A temperatura não influenciou significativamente $(p>0,05)$ na extração quando variou de $50{ }^{\circ} \mathrm{C}$ para $60{ }^{\circ} \mathrm{C}$. Portanto, os resultados demonstraram que a extração conduzida na razão amostra:solvente de 1:50 (m/v), temperatura de $50{ }^{\circ} \mathrm{C}$ e tempo de $90 \mathrm{~min}$ proporcionou $\mathrm{o}$ rendimento de $26,45 \%$. De acordo com os resultados, a tecnologia ultrassônica demonstrou-se efetiva, pois permitiu a obtenção de melhor rendimento quando comparado ao método convencional. $O \mathrm{GE}$ foi de $81,93 \%$ para amostras obtidas por ultrassom nas condições de maior rendimento de pectina.

BONFIETTI, N. F. Desenvolvimento e análise sensorial de cookies de quinoa enriquecidos com pigmentos naturais. Revista Saúde UniToledo, v. 01,

p. 31-46, 2017.
BERNACCI, L.C. et. al.. Passiflora edulis Sims: the (and of others colors). Revista Brasileira de

Fruticultura, v. 30, p. 566-576, 2008. 
CANTERI-SCHEMIN, M. H. et al.. Extraction of pectin from apple pomace. Brazilian Archives of Biology and Technology, v. 48, p. 259-266, 2005.

CHEN, H.; FU, X.; LUO, Z. Properties and extraction of pectin-enriched materials from sugar beet pulp by ultrasonic-assisted treatment combined with subcritical water. Food Chemistry, v. 168, p. 302-310, 2015.

COQUEIRO, A. Y.; PEREIRA, J. R. R.; GALANTE, F. Farinha da casca do fruto de Passiflora edlis $f$. flavicarpa Deg (maracujá-amarelo): do potencial terapêutico aos efeitos adversos. Revista Brasileira de Plantas Medicinais, v. 18, p. 563-569, 2016.

COSTA, A. M. Aproveitamento de subprodutos do maracujá. Embrapa Cerrados, 2013.

GOGATE, P. R.; PANDIT, A. B. Sonochemical reactors: scale up aspects. Ultrasonics

Sonochemistry, v. 11, p. 105-117, 2004.

INSTITUTO ADOLFO LUTZ. Métodos físicoquímicos para analise de alimentos. $4^{\mathrm{a}}$ Ed. Brasília, ANVISA, 2008.

KULKAMI, S. G.; VIJAYANAND, P. Effect of extraction conditions on the quality characteristics of pectin from passion fruit peel (Passiflora edulis f. flavicarpa L.).

Food Science and Technology, v. 43, p. 1026-1031, 2010.

LIEW, S. Q.; CHIN, N. L.; YUSOF, Y. A. Extraction and characterization of pectin from passion fruit peels.

Agriculture and Agricultural Science Procedia, v. 02, p. 231-236, 2014.

MARAN, J. P.; PRIYA, B. Ultrasound-assisted extraction of pectin form sisal waste. Carbohydrate Polymers, v. 115, p. 732-738, 2015.

MELETTI, L. M. M. Avanços na cultura do maracujá no Brasil. Revista Brasileira de Fruticultura, v. 33, p. 83-91, 2011.

MINJARES-FUENTAS, R. et al.. Ultrasound-assisted extraction of pectins from grape pomace using citric acid: a response surfasse methodology approach.

Carbohydrate Polymers, v. 106, p. 179-189, 2014.

MOORTHY, I. G. et al. . Response surfasse optimization of ultrasound assisted extraction of pectin fron pomegranate peel. International Journal of Biological Macromolecules, v. 72, p. 1323-1328, 2015.

OLIVEIRA, C. F. et al.. Extraction of pectin from passion fruit peel using moderate electric field and conventional heating extraction methods. Innovative
Food Science and Emerging Technologies, p. 0108, 2015.

OLIVEIRA, L. F. et al.. Apoveitamento alternativo da casca do maracujá amarelo (Passiflora edulis $\mathrm{F}$. Flavicaspa) para produção de doce em calda. Ciência e Tecnologia de Alimentos, v. 22, n. 03, 2002.

OLIVEIRA, T. I. S. et al.. Optimization of pectin extractiom from banana peels with citric acid by sing response surface methodology, Food Chemistry, v. 198, p. 113-118, 2016.

PINHEIRO, E. R. et al.. Optimization of extraction of high-ester pectin from passion fruit peel (Passiflora edulis Flavicarpa) with citric acid by using response surfasse methodology. Bioresource Technology, v. 99, p. 5561-5566, 2008.

SANTOS, V. A. et al.. Produção e qualidade de frutos de maracujazeiro-amarelo provenientes do cultivo com mudas em diferentes idades. Revista de Ciências Agroveterinárias, v. 16, p. 33-40, 2017.

TOMA, M. et al.. Investigation of the effects of ultrasound on vegetal tissues during solvente extraction. Ultrasonics Sonochemistry, v. 8, p. 137142, 2001.

UCHOA, A. M. A. et al.. Parâmetros físico-químicos, teor de fibra bruta e alimentar de pós alimentícios obtidos de resíduos de frutas tropicais. Segurança Alimentar e Nutricional, v. 15, p. 58-65, 2008.

VILKHU, K. et al.. Applications and opportunities for ultrasound assisted extraction in the food industry. Innovative Food Science Emerging Technology, v. 9, p. 161-169, 2008.

VRIESMANN, L. C.; TEÓFILO, R. F,; PETKOWICZA, C. L. O. Extraction and characterization of pectin from cacao pod husks (Theobroma cacao L.) with citric acid. Food Science and Technology, v. 49, p. 108116, 2012.

WANG, W. et al.. Ultrasound-assisted heating extraction of pectin from grapefruit peel: otimization and comparison with the conventional method. Food Chemistry, v. 178, p. 106-114, 2015.

$X U$, Y. et al.. D. Effects of ultrasound and/or heating on the extraction of pectin from grapefruit peel. Journal of Food Engineering, v. 126, p. 72-81, 2014.

YAPO, B. M. Lemon juice improves the extractability and quality characteristics of pectin from yellow passion fruit by-product as compared with commercial citric acid extractant. Bioresource Technology, v. 100, p. 3147-3151, 2009. 